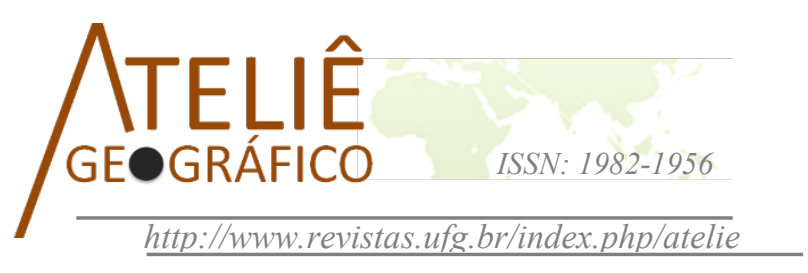

\title{
Estado de conservação da vegetação natural frente às mudanças temporais da paisagem na Bacia Hidrográfica Paraguai/Jauquara, Mato Grosso - Brasil
}

\author{
State of natural vegetation conservation across the \\ landscape temporal changes in Paraguai/Jauquara \\ Hydrographic Basin, in Mato Grosso - Brazil
}

\section{Estado de conservación de la vegetación natural frente a los cambios temporales del paisaje en la Cuenca Hidrográfica Paraguay/Jauquara, Mato Grosso - Brasil}

\author{
Angélica Aparecida Dourado da Costa \\ Universidade do Estado de Mato Grosso \\ angelica.dourado.jna@gmail.com
}
Edinéia Aparecida dos Santos Galvanin
Universidade Estadual Paulista
edineia.galvanin@unesp.br

Elisa Hardt Alves Vieira

Universidade Federal de São Paulo

elisahardt@gmail.com

\begin{abstract}
Resumo
O objetivo deste estudo é analisar temporalmente as mudanças ocorridas na estrutura da paisagem e seus efeitos sobre a conservação da vegetação natural da Bacia Hidrográfica Paraguai/Jauquara-MT. O estudo se justifica pela importância da região hidrográfica e de suas subbacias na contribuição do pulso de inundação do Pantanal mato-grossense. No estudo foram utilizadas imagens dos satélites Landsat-5 e 8, classificadas por uso e cobertura da terra nos anos de 1997, 2007 e 2017. Foram aplicadas sete métricas de paisagem para análise das mudanças ocorridas ao longo do período de 20 anos, por meio de medidas de área, fragmentação, tamanho, conectividade e isolamento da vegetação natural. Os resultados indicaram que 19\% da vegetação natural foi convertida em pastagem, 14\% entre 1997 e 2007 e 4\% entre 2007 e 2017. A agricultura foi responsável por 1\% entre os anos de 1997 e 2007, o que também contribuiu para a fragmentação e aumento no grau de isolamentos dos remanescentes de vegetação da bacia. Desde modo, sugere-se que medidas eficientes
\end{abstract}


sejam adotadas na gestão ambiental, pois a alteração da vegetação natural da área de estudo pode vir a afetar os geossistemas e o pulso de inundação da planície pantaneira.

Palavras-chave: sensoriamento remoto, geotecnologias, ecologia de paisagem, conservação ambiental.

\begin{abstract}
The aim of this study is to analyze the changes in the landscape structure and its effects on the conservation of natural vegetation in the Paraguay/Jauquara-MT Hydrographic Basin. The study is justified by the importance of the hydrographic region and its sub-basins in the contribution of the flood pulse of the Pantanal in Mato Grosso state. In the study, images from the Landsat-5 and 8 satellites were used, classified by land use and land cover in the years 1997, 2007 and 2017. Seven landscape metrics were applied to analyze the changes that occurred over the 20 -year period, through measures of area, fragmentation, size, connectivity and isolation from natural vegetation. The results indicated that $19 \%$ of the natural vegetation was converted by pasture, 14\% between 1997 and 2007 and 4\% between 2007 and 2017 . Agriculture was responsible for 1\% of the vegetation between 1997 and 2007, which also contributed to fragmentation and an increase in the degree of isolation from the remaining vegetation in the basin. Therefore, it is suggested that efficient measures be adopted in environmental management, as the alteration of the natural vegetation in the study area may affect the geosystems and the flood pulse of the Pantanal plain.

Keywords: remote sensing, geotechnology, landscape ecology, environmental conservation.
\end{abstract}

\begin{abstract}
Resumen
El objetivo de este estudio es analizar los cambios en la estructura del paisaje y sus efectos sobre la conservación de la vegetación natural en la Cuenca Hidrográfica Paraguay / Jauquara-MT. El estudio se justifica por la importancia de la región hidrográfica y sus subcuencas en la contribución del pulso de inundación del Pantanal en Mato Grosso. En el estudio, se utilizaron imágenes de los satélites Landsat-5 y 8, clasificados por uso del suelo y cobertura del suelo en los años 1997, 2007 y 2017. Se aplicaron siete métricas de paisaje para analizar los cambios que ocurrieron durante el período de 20 años, por medio de medidas de área, fragmentación, tamaño, conectividad y aislamiento de la vegetación natural. Los resultados indicaron que el $19 \%$ de la vegetación natural fue convertida por pastos, el $14 \%$ entre 1997 y 2007 y el $4 \%$ entre 2007 y 2017 . La agricultura convirtió el $1 \%$ de la vegetación entre 1997 y 2007, lo que también contribuyó a la fragmentación y el aumento en el grado de aislamiento de la vegetación restante en la cuenca. Por lo tanto, se sugiere que se adopten medidas eficientes en la gestión ambiental, ya que la alteración de la vegetación natural en el área de estudio puede afectar los geosistemas y el pulso de inundación de la llanura del Pantanal.

Palabras clave: sensorización remota, geotecnologías, ecología de paisaje, espacialización, conservación ambiental.
\end{abstract}

\title{
Introdução
}

O estado de conservação dos ambientes naturais é uma recorrente preocupação entre a comunidade cientifica, pois segundo Wiens (2012) o ritmo das mudanças vem sendo acelerado em virtude do crescimento populacional e de seus anseios políticos, sociais, culturais e econômicos e, dessa forma, o homem pode estar exaurindo os componentes naturais. 
Nesse contexto, a ecologia de paisagem pode ser utilizada para compreensão da heterogeneidade espacial, por meio de duas vertentes, a primeira geográfica que busca compreender a influência das ações antrópicas sobre a paisagem e a segunda é a ecológica que analisa a consequência dos arranjos espaciais da paisagem sobre os processos ecológicos e seus efeitos sobre a conservação dos ecossistemas (PIVELLO; METZGER, 2007; METZGER, 2001).

Amorim e Oliveira (2008) esclarecem que a análise de paisagem está alicerçada em estudos setoriais ou integrada a aspectos físicos, econômicos e sociais, permitindo identificar e avaliar impactos ambientais sob o reconhecimento de áreas de riscos, categorizadas como unidades geoambientais. Isso possibilita, uma análise rigorosa e criteriosa sobre a vulnerabilidade e ocorrência de fenômenos que podem resultar em efeitos sociais, econômicos e ambientais.

Neste sentido, as métricas de paisagem possibilitam analisar padrões estruturais da paisagem (MCGARIGAL; MARKS, 1995), que operacionalizadas via geotecnologias têm-se mostrado eficientes para compreender as mudanças temporais dos padrões estruturais da paisagem e seus efeitos sobre a conservação da vegetação em ambientes vulneráveis à ação antrópica em bacias hidrográficas, conforme observados nos trabalhos de Morais e Carvalho (2013), Neves, Neves e Neves (2014), Pereira et al. (2001), Hardt, Santos e Pereira-Silva (2014) e Romero et al. (2018).

Nessa perspectiva, o objetivo deste estudo é analisar temporalmente as mudanças ocorridas na estrutura da paisagem e seus efeitos sobre a conservação da vegetação natural da Bacia Hidrográfica Paraguai/Jauquara (BHPJ) e de suas subbacias.

O estado de conservação da vegetação natural da BHPJ é uma questão preocupante, pois sua extensa área de drenagem localiza-se em regiões de Planalto da Bacia do Alto Paraguai, que é uma unidade hidrográfica que contêm o bioma e a planície alagável pantaneira, e suas águas contribuem diretamente no pulso de inundação do Pantanal mato-grossense (PESSOA et al., 2013). Deste modo, com base nas mudanças temporais dos padrões estruturais da paisagem, este estudo contribuirá na compreensão de como o estado de conservação da vegetação nativa da bacia de estudo pode influenciar na manutenção dos geossistemas e no pulso de inundação do Pantanal matogrossense.

\section{Material e métodos}

\section{Área de estudo}

A Bacia Hidrográfica Paraguai/Jauquara (BHPJ), que está localizada na região nordeste da Bacia do Alto Paraguai (BAP), no Mato Grosso, possui extensão territorial de $16.482 \mathrm{~km}^{2}$ e compreende 9 subbacias tributárias, sendo elas: a do Rio Santana, Rio Diamantino, Rio dos Bugres, Rio Branco, Interbacia do Rio Paraguai Médio, Rio Pari, Rio Jauquara, Córrego Salobra e Córrego Cachoerinha (Figura 01). 


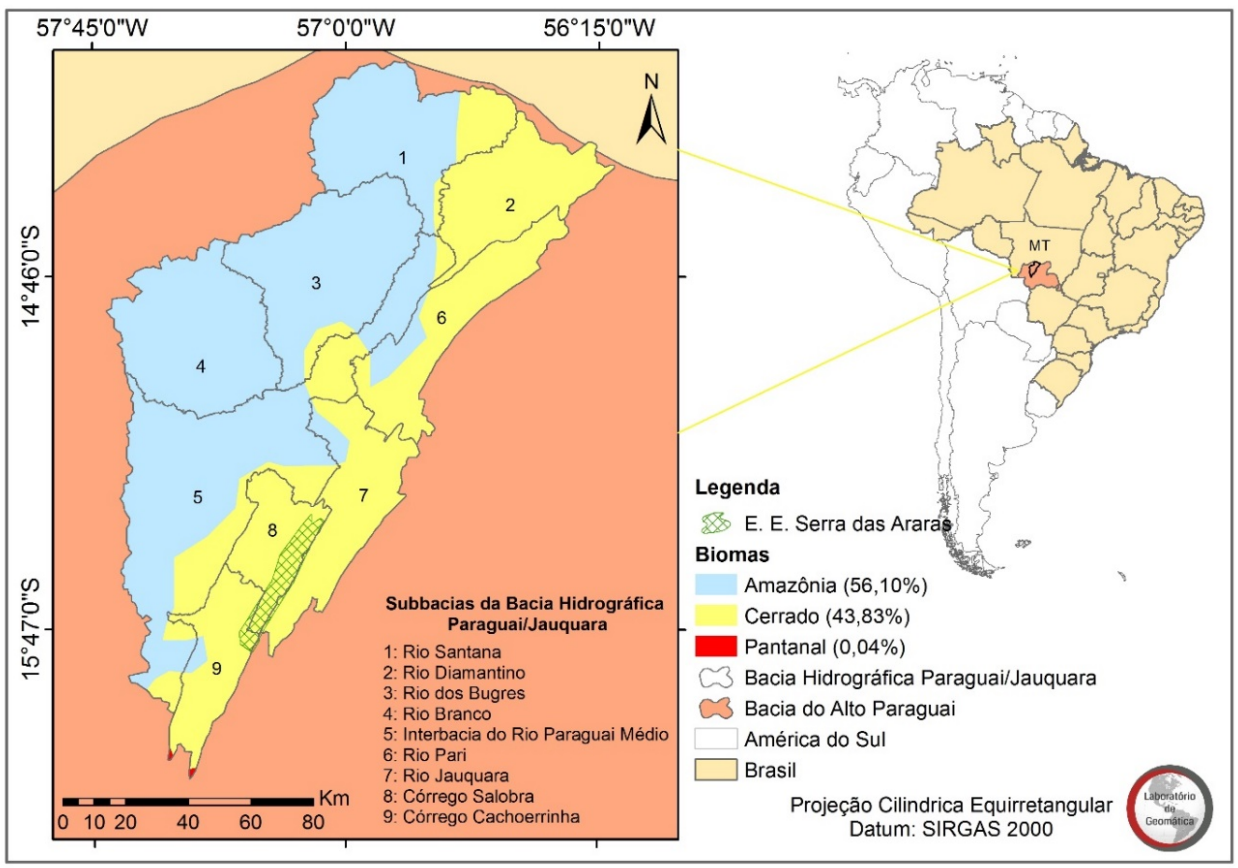

Figura 01. Bacia Hidrográfica Paraguai/Jauquara - MT nos contextos: brasileiro, estadual, da BAP, dos biomas nacionais e das unidades hidrográficas. Fonte. Elaborado pelos autores no dia 18 de agosto de 2018

De acordo com Fenner et al. (2014), o clima na BHPJ é Tropical e as precipitações ocorrem entre a primavera e o verão. As normais climatológicas do Instituto Nacional de Meteorologia (INMET) indicam que a precipitação média no ano de 2017 foi de $161 \mathrm{~mm}$, sendo a máxima de $473 \mathrm{~mm}$ no mês de fevereiro e a mínima de $0 \mathrm{~mm}$ nos meses de junho e julho do mesmo ano (INMET, 2020).

A cobertura vegetal da BHPJ é composta por remanescentes de Florestas Estacionais e Savanas, típicas dos três biomas nacionais que abrangem sua área de drenagem, Amazônia (56,10\%), Cerrado (43,83\%) e Pantanal (0,04\%) (BRASIL, 2004; IBGE, 2012).

O relevo varia de Plano a Ondulado da região noroeste a sudoeste da BHPJ com altitudes que variam de 100 a $500 \mathrm{~m}$, em área do bioma Amazônia. Na região sudoeste da BHPJ, em área de cerrado, o relevo varia de Forte Ondulado a Escarpado, predominando cotas acima de $700 \mathrm{~m}$ de altura, onde abriga a estação ecológica Serra das Araras, que é uma unidade de conservação de proteção integral, que se estende por 271 $\mathrm{km}^{2}$ entre os municípios de Cáceres e Porto Estrela. Essa estação foi criada pelo decreto $\mathrm{n}^{\circ} 87.222$ de 31 de maio de 1982 e é a única unidade de conservação da BHPJ (BRASIL, 1982). 
A região da BHPJ vem passando por mudanças na paisagem desde meados do século XIX decorrentes da exploração madeireira e mineração e, posteriormente, pelo desenvolvimento de atividade agrícolas (FERREIRA, 2001).

\section{Procedimentos metodológicos}

A delimitação da BHPJ e de suas subbacias foi realizada por meio do Modelo digital de Elevação (MDE), derivado do Shutter Radar Topography Mission (SRTM) com resolução espacial de 30 m, reprojetado para o Datum SIRGAS 2000, fuso 21 Sul, no software QGIS (versão 2.14.21) (QGIS DEVELOPMENT TEAM, 2016).

Para elaboração do mapa de uso e cobertura da terra na Bacia Hidrográfica Paraguai/Jauquara foram utilizadas as imagens com resolução espacial de $30 \mathrm{~m}$ do satélite Landsat-8, sensor Operational Land Imager (OLI) e Thematic Mapper (TM) do Lansdsat-5 ambas referentes à orbita 227 e pontos 070 e 071, respectivamente, imageadas nos dias 16/06/2017, 19/08/2017, 21/06/2007, 21/06/2007, 25/06/1997 e 25/06/1997. Estas foram reprojetadas para o Datum SIRGAS 2000, fuso 21 Sul, no software QGIS. As imagens Landsat-5 foram georreferenciadas no Sistema de Processamento de Informações Georreferenciadas (SPRING) (versão 5.5.2) (CÂMARA et al., 1996), utilizando como referência as imagens do Landsat- 8 , com tolerância mínima de erro de 0,5 por pixel. Após o procedimento anterior a resolução radiométrica das imagens foram padronizadas para 8 bits, no software ArcGIS (versão 10.3) (ESRI, 2007).

Todas as imagens foram segmentadas por meio do algoritmo de crescimento de regiões no software SPRING, adotando similaridade e área de pixel diferentes para os anos do estudo, pois os valores aplicados foram os que melhor representaram as regiões para cada ano após a realização de testes (Quadro 01).

Quadro 01. Relação de Segmentação por similaridade e área de pixel utilizados para classificação do uso e cobertura da terra na Bacia Hidrográfica Paraguai/Jauquara - MT.

\begin{tabular}{|cccc|}
\hline Satélite & Ano do imageamento & Similaridade & Área de pixel \\
\hline Landsat -8 & 2017 & 3 & 40 \\
Landsat -5 & 2007 & 2 & 50 \\
Landsat-5 & 1997 & 3 & 40 \\
\hline
\end{tabular}

As amostras das classes do uso e cobertura da terra, elencadas no Quadro 02, foram utilizadas com o objetivo de treinar o algoritmo Bhattacharya do software SPRING, com limiar de aceitação de $95 \%$. O produto da classificação foi um arquivo raster (matricial), que foi convertido para vetorial e exportado no formato shapefile. $\mathrm{O}$ processo de edição das classes de uso e cobertura da terra, elaboração do layout e quantificação da área ocupada pelas classes foram efetuados no software ArcGIS. 
Quadro 02. Relação de classes utilizadas para classificação do uso e cobertura da terra na Bacia Hidrográfica Paraguai/Jauquara

\begin{tabular}{|l|l|}
\hline \multicolumn{1}{|c|}{ Classes } & \multicolumn{1}{c|}{ Descrição } \\
\hline Agricultura & Todos os tipos de culturas agrícolas \\
Corpos d'água & Lagos artificiais, lagoas, rios e espelho d'água \\
Mancha urbana & Cidades e distritos \\
Outros usos & Estradas vicinais, rodovias, construções civis e mineração \\
Pastagem & Pecuária \\
Vegetação natural & Savana e Floresta Estacional \\
\hline
\end{tabular}

As mudanças históricas de uso e cobertura da terra foram calculadas a partir da tabulação cruzada e representadas a partir tabelas de perdas e ganhos do uso e cobertura da terra (ROMERO, et al. 2018) do período de avaliação para a BHPJ e de suas subbacias, facilitando a visualização e interpretação dos efeitos das mudanças ocorridas sobre a conservação da vegetação natural da bacia ao longo do tempo.

A análise das mudanças da estrutura da paisagem e seus efeitos sobre o estado de conservação da vegetação natural da BHPJ foi realizada por meio da aplicação de um conjunto de métricas de paisagem sobre os mapas históricos de uso e cobertura da terra. Foram selecionadas métricas que avaliassem as mudanças em composição e configuração dos elementos constituintes da paisagem ao longo de 20 anos, através de medidas de área da paisagem (CA, PLAND) e de fragmentação (NP), tamanho (LPI), conectividade (COHESION) e isolamento (ENN_MN) dos fragmentos de vegetação natural (Quadro 03). As métricas foram calculadas no software Fragstats (versão 4.2.1) (MCGARIGAL; MARKS, 1995).

Quadro 03. Relação de métricas utilizadas para analisar a estrutura da paisagem da Bacia Hidrográfica Paraguai/Jauquara - MT

\begin{tabular}{|c|c|c|}
\hline Métricas & Fórmulas & Conceitos \\
\hline $\begin{array}{c}\text { Área da } \\
\text { classe (CA) }\end{array}$ & CA: Área da Classe, aj: área do fragmento j. & $\begin{array}{c}\text { Área total de cada } \\
\text { classe em unidade de } \\
\text { área }\left(\mathrm{km}^{2}\right) \\
\text { (MCGARIGAL; } \\
\text { MARKS, 1995) }\end{array}$ \\
\hline $\begin{array}{c}\text { Porcentagem } \\
\text { da Paisagem } \\
\text { (PLAND) }\end{array}$ & $\sum_{j=1}^{n} a_{j} a_{j}$ & $\begin{array}{c}\text { Porcentagem total de } \\
\text { cada classe referente a } \\
\text { paisagem (\%) } \\
\text { (MCGARIGAL; } \\
\text { MARKS, 1995) }\end{array}$ \\
\hline $\begin{array}{c}\text { pi: Proporção da classe i, aj: área do fragmento j, A: } \\
\text { área total da paisagem. }\end{array}$ & \\
\hline
\end{tabular}




\begin{tabular}{|c|c|c|}
\hline Métricas & Fórmulas & Conceitos \\
\hline $\begin{array}{l}\text { Número de } \\
\text { fragmentos } \\
\text { (NP) }\end{array}$ & $\mathrm{n}_{\mathrm{i}}$ : Número de fragmentos por classe $\mathrm{i}$. & $\begin{array}{c}\text { Número de fragmentos } \\
\text { por classe } \\
\text { (MCGARIGAL; } \\
\text { MARKS, 1995) }\end{array}$ \\
\hline $\begin{array}{c}\text { Índice de } \\
\text { maior macha } \\
\text { (LPI) }\end{array}$ & $\begin{array}{c}L P I=\frac{\max _{j=1}^{n}\left(a_{j}\right)}{A}(100) \\
\mathrm{aj}_{\mathrm{j}} \text { Área do maior fragmento } \mathrm{j}, \mathrm{A}: \text { Área total da } \\
\text { paisagem. }\end{array}$ & $\begin{array}{c}\text { Porcentagem da } \\
\text { paisagem ocupada pela } \\
\text { área da maior mancha } \\
\text { da classe vegetação } \\
\text { natural }(\%) \\
\text { (MCGARIGAL; } \\
\text { MARKS, 1995) }\end{array}$ \\
\hline $\begin{array}{l}\text { Índice de } \\
\text { coesão de } \\
\text { mancha } \\
\text { (COHESIO } \\
\quad \mathrm{N})\end{array}$ & $\begin{array}{c}\text { COHESION }=\left[1-\frac{\sum_{j=1}^{n} p_{j}}{\sum_{j=1}^{n} p_{j} \sqrt{a_{j}}}\right]\left[1-\frac{1}{\sqrt{A}}-\right. \\
\text { A: Área total da paisagem, pj: perímetro do } \\
\quad \text { fragmento j, aj: Área do fragmento j. }\end{array}$ & $\begin{array}{l}\text { Corresponde a soma da } \\
\text { conectividade física } \\
\text { entre cada fragmento } \\
\text { da mesma classe. Pode } \\
\text { variar de } 0 \text { a } 100 \text {, sendo } \\
100 \text { o valor máximo de } \\
\text { coesão da classe } \\
\text { vegetação natural } \\
\text { (MCGARIGAL; } \\
\text { MARKS, 1995) }\end{array}$ \\
\hline $\begin{array}{c}\text { Distância } \\
\text { euclidiana } \\
\text { de vizinho } \\
\text { mais } \\
\text { próximo } \\
\text { (ENN_MN) }\end{array}$ & $\begin{array}{l}\text { MN: média do somatório das distâncias dos } \\
\text { fragmentos de vizinhança mais próxima com o } \\
\text { mesmo por tipo de classe } \mathrm{ij}, \mathrm{n}_{\mathrm{i}} \text { : Número de } \\
\text { fragmentos da classe } \mathrm{i} \text {. }\end{array}$ & $\begin{array}{l}\text { Média do somatório de } \\
\text { todas as distâncias } \\
\text { entre cada fragmento e } \\
\text { o vizinho mais próximo } \\
\text { da mesma classe, } \\
\text { dividido pelo número } \\
\text { de fragmentos da classe } \\
\text { (MCGARIGAL; } \\
\text { MARKS, 1995) }\end{array}$ \\
\hline
\end{tabular}

\section{Resultados e discussão}

A área total da paisagem da BHPJ abrange $16.482 \mathrm{~km}^{2}$, dos quais $54 \%$ esteve coberta por remanescentes de vegetação nativa de savanas e florestas estacionais em 2017. Embora a vegetação nativa ainda seja predominante na área de estudo, há duas décadas sua porcentagem na paisagem (PLAND) era 10\% maior (Figura 02). 


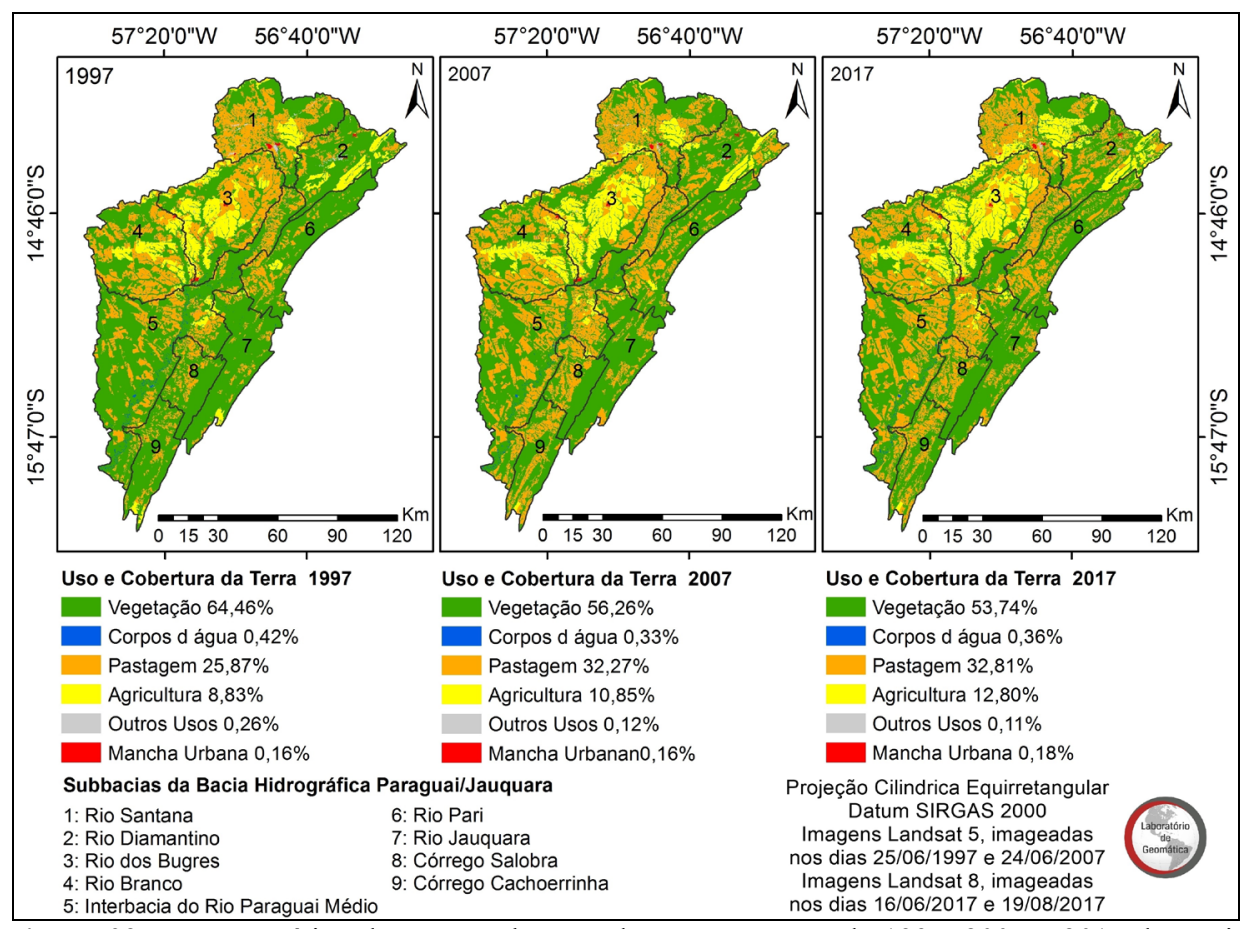

Figura 02: Mapa temático do uso e cobertura da terra nos anos de 1997, 2007 e 2017 da Bacia Hidrográfica Paraguai/Jauquara - MT. Fonte. Elaborado pelos autores no dia 10 de agosto de 2018

O mapa temático permitiu identificar que o uso da terra para pastagem aumentou 6,4\% entre os anos de 1997 a 2007 e depois estabilizou no segundo período entre 2007 a 2017. O contrário disso ocorreu no uso da terra para agricultura, pois houve incremento gradativo da porcentagem de área ao longo dos anos na BHPJ (Figura 02).

Os resultados indicam que as subbacias do Córrego Cachoerinha, Interbacia do Paraguai Médio e Rio Diamantino da BHPJ apresentaram maiores reduções na PLAND da vegetação natural, principalmente entre o período de 1997 e 2007 (Tabela 01).

As porcentagens de áreas de vegetação nativa convertidas nessas subbacias é uma condição preocupante, já que o Rio Paraguai, canal principal da BHPJ, nasce na subbacia do Rio Diamantino e é drenado até o exutório pela extensa Interbacia do Paraguai Médio. Portanto, essas áreas desempenham importante papel sobre a dinâmica hídrica da área de estudo e assim sendo é valido a preocupação, pois a conversão da vegetação nativa por usos antrópicos pode tornar essas importantes subbacias mais vulneráveis.

Tucci (2001) esclarece a importância dos remanescentes de vegetação nativa, principalmente das matas ciliares para os recursos hídricos, pois reduzem o incremento da carga de sedimentos e de agentes poluidores que assoariam e desqualificam a água. 
Para Oliveira filho, Dutra e Ceruti (2012) os impactos ambientais não ocorrem de forma pontual em uma bacia hidrográfica, isso porque os canais de drenagem perpetuam o impacto por toda área de domínio da bacia.

Tabela 01: Redução e aumento das porcentagens na paisagem (PLAND) da vegetação natural da Bacia Hidrográfica do Paraguai/Jauquara - MT entre os períodos de 1997 a 2007 e 2007 a 2017

\section{Redução e aumento da PLAND da vegetação natural (\%)}

\begin{tabular}{l|c|c|c|c}
\hline \multirow{2}{*}{\multicolumn{1}{c|}{ Subbacias da BHPJ }} & \multicolumn{2}{c|}{1997 x $2007(\%)$} & \multicolumn{2}{c}{2007 x $2017(\%)$} \\
\cline { 2 - 5 } & Aumento & Redução & Aumento & Redução \\
\hline Rio Santana & & 0,09 & & 2,91 \\
\hline Rio Bugres & & 4,09 & & 2,02 \\
\hline Rio Jauquara & & 6,59 & & 2,21 \\
\hline Rio Pari & & 7,02 & & 4,54 \\
\hline Rio Diamantino & & 7,56 & & 6,54 \\
\hline Rio Branco & & 10,28 & & 2,82 \\
\hline Córrego Salobra & & 13,00 & & 0,00 \\
\hline Interbacia do Paraguai Médio & & 16,53 & & 0,32 \\
\hline Córrego Cachoerinha & & & & \\
\hline
\end{tabular}

O aumento de $0,22 \%$ da vegetação natural na subbacia do Córrego Salobra entre o período de 2007 a 2017 foi considerado insignificante frente a redução de $10,76 \%$ da vegetação no período anterior (Tabela 01 ).

A tabulação cruzada indicou que as áreas cobertas por vegetação nativa foram convertidas para pastagem e agricultura, em aproximadamente $28 \%, 26 \%$ e $25 \%$ nas subbacias do Rio Branco, Córrego Cachoerinha Interbacia do Paraguai Médio e na subbacia do Rio Diamantino, respectivamente entre 1997 e 2017. Houve também nas subbacias conversão da vegetação por agricultura, contudo mantiveram-se abaixo dos $2 \%$ com exceção a subbacia do Rio Bugres cuja conversão foi de 6,29\% entre o período de 2007 a 2017 (Tabela 02).

Tabela 02: Relação de perdas da vegetação natural para os usos antrópicos pastagem e agricultura nas subbacias da Bacia Hidrográfica do Paraguai/Jauquara - MT entre os períodos de 1997 a 2007 e 2007 a 2017.

\begin{tabular}{|c|c|c|c|c|c|c|c|}
\hline \multirow{2}{*}{ Subbacias da BHPJ } & \multicolumn{2}{|c|}{1997 x 2007 (\%) } & \multicolumn{2}{|c|}{2007 x 2017 (\%) } & \multicolumn{3}{c|}{ Total de perda da vegetação } \\
\cline { 2 - 8 } & Pastagem & Agricultura & Pastagem & Agricultura & Pastagem & Agricultura & Total \\
\hline Rio Branco & 18,8 & 1,67 & 7,24 & 0,09 & 26,04 & 1,76 & 28 \\
\hline Córrego Cachoerinha & 25,83 & 0 & 0,4 & 0,09 & 26,23 & 0,09 & 26 \\
\hline $\begin{array}{c}\text { Interbacia do Paraguai } \\
\text { Médio }\end{array}$ & 21,52 & 0,61 & 2,67 & 0,06 & 24,19 & 0,67 & 25 \\
\hline Rio Diamantino & 12,32 & 0,82 & 11,1 & 0,6 & 23,42 & 1,42 & 25 \\
\hline
\end{tabular}




\begin{tabular}{|c|c|c|c|c|c|c|c|}
\hline \multirow{2}{*}{ Subbacias da BHPJ } & \multicolumn{2}{|c|}{$1997 \times \mathbf{2 0 0 7}(\%)$} & \multicolumn{2}{|c|}{$\mathbf{2 0 0 7} \times \mathbf{2 0 1 7}(\mathbf{\%})$} & \multicolumn{3}{|c|}{ Total de perda da vegetação } \\
& Pastagem & Agricultura & Pastagem & Agricultura & Pastagem & Agricultura & Total \\
\hline & 7,13 & 5,27 & 5,43 & 1,02 & 12,56 & 6,29 & 19 \\
\hline Rio Bugres & 9,56 & 0 & 6,45 & 0,07 & 16,01 & 0,07 & 16 \\
\hline Rio Pari & 15,68 & 0,27 & 0 & 0 & 15,68 & 0,27 & 16 \\
\hline Córrego Salobra & 8,13 & 0 & 2,41 & 0,29 & 10,54 & 0,29 & 11 \\
\hline Rio Jauquara & 0,74 & 0,26 & 5,25 & 1,23 & 5,99 & 1,49 & 7 \\
\hline Rio Santana & & & & & & \\
\hline
\end{tabular}

Segundo Krusche et al. (2005), historicamente os desmatamentos em florestas tropicais são ocasionados pela demanda populacional e por consequência da expansão das pastagens e lavouras, principalmente pela expansão de áreas de pastagens para a criação de gado em ambientes florestais amazônicos (RIVERO et al., 2009). Cunha (2006) acrescenta que, em virtude dos processos de ocupação e incentivos governamentais após a década de 1960, a economia do estado de Mato Grosso possui caráter essencialmente agrícola, destacando a pecuária como uma medida alternativa e imediata para a valoração da terra durante o processo de ocupação do estado e esclarece que a atividade vem pressionando cada vez mais os remanescentes de vegetação nativa desde o início do processo.

Neste sentido, as áreas convertidas deixaram de cumprir seu papel ecossistêmico, pois em áreas agrícolas os processos essenciais de ciclagem de nutrientes e fixação do carbono no solo são reduzidos, principalmente em áreas de pastagens degradadas e não manejadas (ROSOLEN et al., 2012).

Oliveira e Corsi (2005) explicam que a recuperação de pastagens degradadas é de suma importância, pois evita o desmatamento de novas áreas. Neste sentido, o manejo adequado da pastagem para criação de gado de corte causa menos danos ao meio ambiente do que áreas utilizadas para agricultura, pois a pastagem cobre a terra durante todo o período de uso, sem interrupção, e por esse motivo tem potencial para reduzir a velocidade do escoamento superficial, diminuindo a erosão e lixiviação do solo (PINTO et al., 2005).

As áreas de vegetação nativa convertidas nas 9 subbacias da BHPJ totalizam $1.766 \mathrm{~km}^{2}$ para outros usos antrópicos, pois entre 1997 e 2007 a área reduziu $8,19 \%$, equivalente a $1.350 \mathrm{~km}^{2}$, e após esse período mais $2,53 \%$, com $416 \mathrm{~km}^{2}$ desmatados (Figura 03). No primeiro período os usos antrópicos pastagem e agricultura aumentaram $6,40 \%$ e $2,02 \%$, respectivamente (Figura 03 ). 


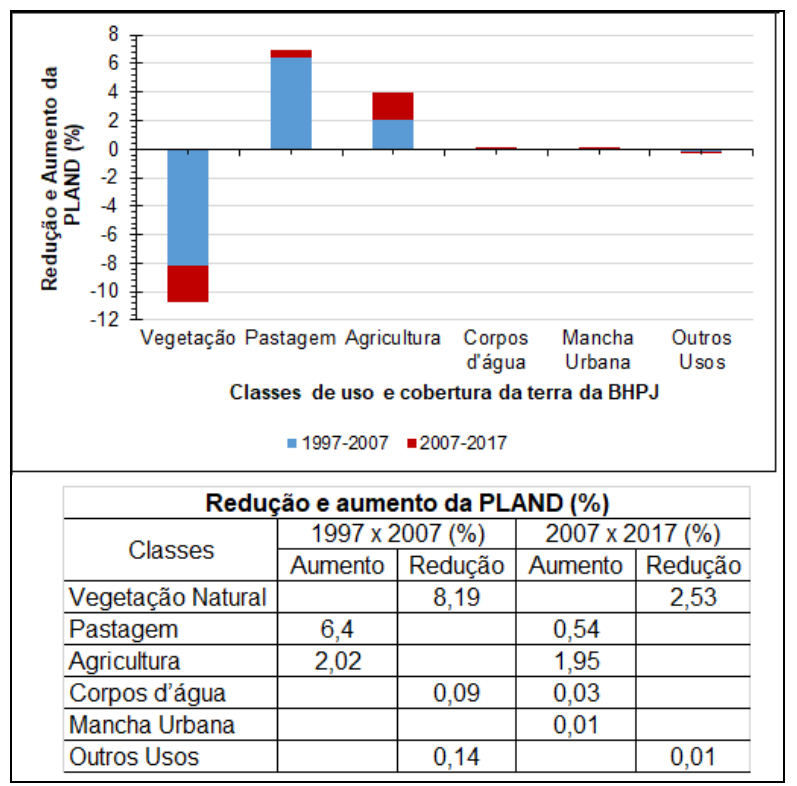

Figura 03: Redução e aumento das porcentagens de uso e cobertura da terra (PLAND) da Bacia Hidrográfica do Paraguai/Jauquara - MT entre os períodos de 1997 a 2007 e 2007 a 2017 Fonte. Elaborado pelos autores.

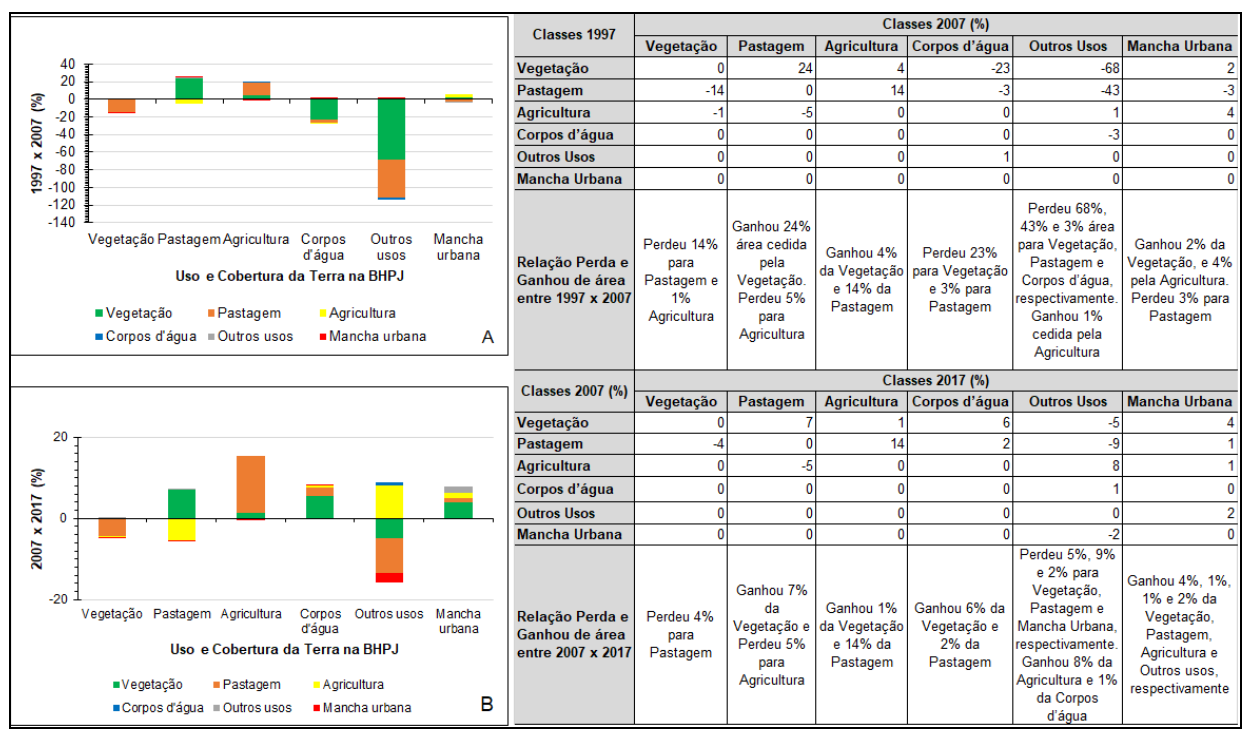

Figura 04: Mudanças (Perdas e Ganhos) entre uso e cobertura da terra na paisagem da Bacia Hidrográfica Paraguai/Jauquara - MT entre os períodos de 1997 a 2007 (A) e 2007 a 2017 (B). Fonte: Elaborado pelos autores. 
Ao longo dos 20 anos houve uma expansão de 33\% da classe agricultura na BHPJ, 18\% no período de 1997 a 2007 e 15\% no segundo período. Os resultados apontam que essa expansão aconteceu pela conversão de $4 \%$ dos remanescentes de vegetação nativa e 14\% pela substituição de áreas de pastagem nos anos de 1997 a 2007. No período de 2007 e 2017 a vegetação foi convertida em 1\% para a agricultura e a pastagem em 14\% (Figura 04).

Esse tipo de substituição foi mais representativo nas subbacias do Rio dos Bugres e Rio Santana ao longo dos 20 anos, isso porque a PLAND da classe pastagem reduziu $11 \%$ e $6 \%$, ao passo que a agricultura aumentou $17 \%$ e $10 \%$, respectivamente ao longo do período. O feito ocorreu, pois 59\% e $25 \%$ das áreas dessas bacias destinadas para pastagem foram substituídas para agricultura, nas subbacias do Rio dos Bugres e Rio Santana, respectivamente. As mudanças ocorreram principalmente nas regiões Sudoeste e Leste da subbacia do Rio Santana e nas regiões Centro-oeste e Norte da Rio dos Bugres (Figura 05).

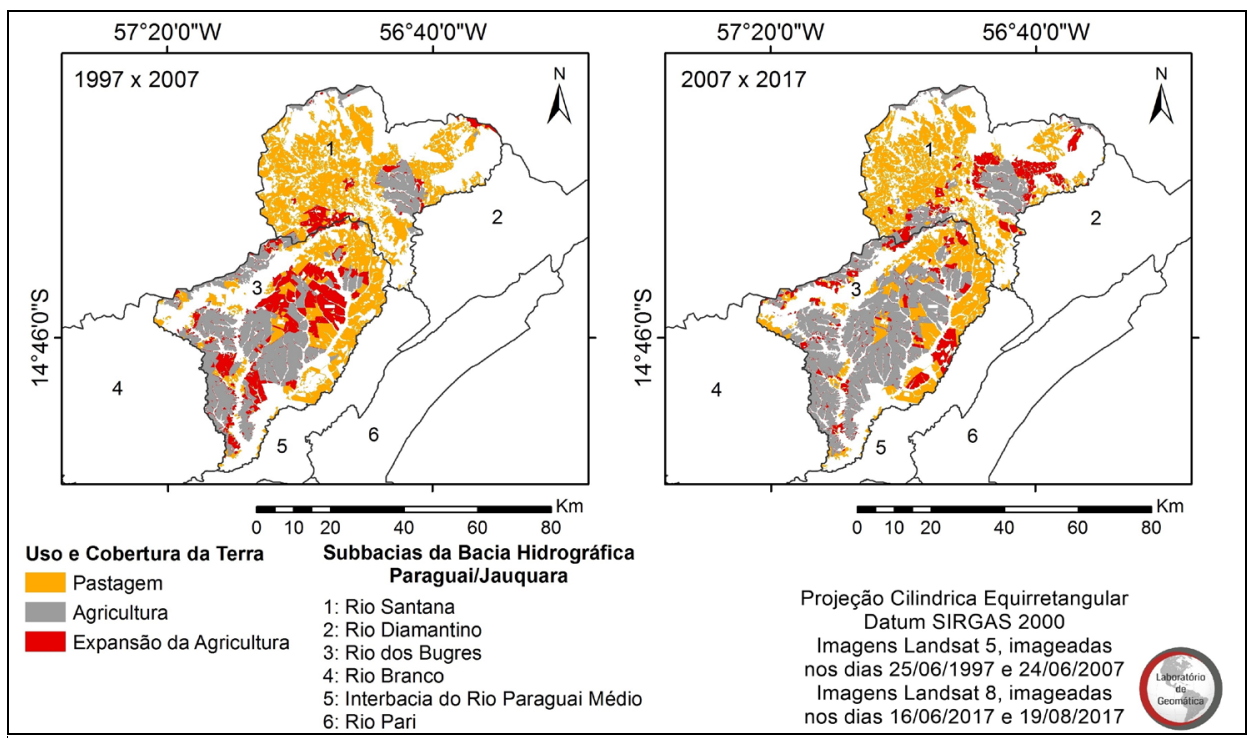

Figura 05: Uso da terra para Pastagem substituído por Agricultura nas Bacias Rio dos Bugres e Santana, subbacias da Bacia Hidrográfica Paraguai/Jauquara - MT dos períodos 1997 a 2007 e 2007 a 2017.

Fonte. Elaborado pelos autores no dia 18 de agosto de 2018

Ribeiro, Galvanin e Paiva (2017) relacionam a mudança do uso da terra de pastagem para agricultura na BHPJ com a instalação de duas usinas, uma em Barra do Bugres e outra em Nova Olímpia, que juntas utilizam aproximadamente 97 mil hectares destinados ao plantio de cana-de-açúcar para a produção de açúcar e álcool. 
$\mathrm{Na}$ comparação entre as subbacias da BHPJ, os resultados indicam que as mudanças nos padrões de estrutura da paisagem ocorreram de formas diferentes, com efeitos distintos sobre a conservação da vegetação natural da bacia. Isso porque as subbacias que mantiveram remanescentes de vegetação nativa com maior representatividade foram Rio Jauquara, Rio Pari e Córrego Salobra (Tabela 3), pois as mesmas localizam-se próximas do divisor topográfico da BHPJ, onde o relevo é mais dissecado com altitudes elevadas, o que dificulta o desenvolvimento de atividades agrícolas. Além disso, a subbacia do Córrego Salobra abriga a Estação Ecológica Serra das Araras, única unidade de conservação da BHPJ, na qual é proibida a substituição da vegetação natural por usos antrópicos (BRASIL, 1982).

Em 2017 as subbacias com menor PLAND da vegetação natural são as do Rio dos Bugres, Rio Branco e Rio Santana (Tabela 3). Os valores são considerados baixos, isso porque a área coberta por vegetação nativa não ultrapassa os $50 \%$ da paisagem e neste caso, o elemento que está dominando é de origem antrópica. Na subbacia do Rio dos Bugres a agricultura representa $45 \%$ da paisagem, já na Bacia do Rio Branco a pastagem representa $42 \%$. Por outro lado, na subbacia do Rio Santana, os usos antrópicos pastagem e agricultura abarcam $54 \%$ da paisagem.

Tabela 03: Variações na porcentagem na paisagem (PLAND) da vegetação natural das subbacias da Bacia Hidrográfica Paraguai/Jauquara - MT nos anos de 1997, 2007 e 2017.

\begin{tabular}{l|c|c|c}
\hline \multirow{2}{*}{ Subbacias da BHPJ } & \multicolumn{3}{c}{ PLAND da vegetação natural (\%) } \\
\cline { 2 - 4 } & $\mathbf{1 9 9 7}$ & $\mathbf{2 0 0 7}$ & $\mathbf{2 0 1 7}$ \\
\hline Rio Jauquara & 88,37 & 81,78 & 79,57 \\
\hline Rio Pari & 80,99 & 73,97 & 69,43 \\
\hline Córrego Salobra & 78,28 & 67,52 & 67,74 \\
\hline Córrego Cachoerinha & 81,02 & 64,49 & 64,16 \\
\hline Interbacia do Paraguai Médio & 72,66 & 59,66 & 58,06 \\
\hline Rio Diamantino & 69,11 & 61,55 & 55,01 \\
\hline Rio Santana & 48,23 & 48,14 & 45,22 \\
\hline Rio Branco & 48,81 & 40,53 & 37,71 \\
\hline Rio dos Bugres & 37,75 & 33,66 & 31,64 \\
\hline
\end{tabular}

Na avaliação das mudanças no estado de conservação da vegetação natural da BHPJ, os resultados apontaram que o Número de Fragmentos (NP) aumentou de 1.578 para 2.012 e que houve a redução de 11\% do Índice de Maior Mancha (LPI), entre 1997 a 2017 (Tabela 4). Concomitante a substituição da vegetação nativa por usos antrópicos, esses dados são indícios de que as mudanças ocorridas nos últimos 20 anos tenham 
promovido ou agravado o processo de fragmentação, bem como o estado de conservação da área de estudo.

Tabela 04: Número de Fragmentos (NP) e Índice de Maior Fragmento (LPI) calculados por subbacia da Bacia Hidrográfica Paraguai/Jauquara - MT nos anos de 1997, 2007 e 2017.

\begin{tabular}{|c|c|c|c|c|c|c|c|c|c|c|}
\hline \multirow[b]{2}{*}{ Subbacias } & \multicolumn{3}{|c|}{ NP } & \multicolumn{2}{|c|}{$\begin{array}{c}\text { Redução e } \\
\text { aumento }\end{array}$} & \multicolumn{3}{|c|}{ LPI (\%) } & \multicolumn{2}{|c|}{$\begin{array}{c}\text { Redução e } \\
\text { aumento }\end{array}$} \\
\hline & 1997 & 2007 & 2017 & $\begin{array}{c}1997 \\
x \\
2007 \\
\end{array}$ & $\begin{array}{c}2007 \\
x \\
\mathbf{2 0 1 7} \\
\end{array}$ & 1997 & 2007 & 2017 & $\begin{array}{c}1997 \\
x \\
2007 \\
\end{array}$ & $\begin{array}{c}2007 \\
\mathbf{x} \\
\mathbf{2 0 1 7} \\
\end{array}$ \\
\hline $\begin{array}{l}\text { Córrego } \\
\text { Cachoerinha }\end{array}$ & 60 & 129 & 131 & +69 & +2 & 80 & 62 & 63 & -18 & +1 \\
\hline Córrego Salobra & 58 & 86 & 73 & +28 & -13 & 77 & 65 & 65 & -12 & 0 \\
\hline $\begin{array}{l}\text { Interbacia do } \\
\text { Paraguai Médio }\end{array}$ & 334 & 464 & 453 & +130 & -11 & 45 & 46 & 45 & +1 & -1 \\
\hline Rio Branco & 211 & 207 & 264 & -4 & +57 & 45 & 37 & 20 & -8 & -17 \\
\hline Rio Diamantino & 103 & 115 & 179 & +12 & +64 & 66 & 58 & 52 & -8 & -5 \\
\hline Rio dos Bugres & 287 & 274 & 321 & -13 & +47 & 32 & 17 & 26 & -15 & +9 \\
\hline Rio Jauquara & 42 & 72 & 89 & +30 & +17 & 88 & 80 & 78 & -8 & -2 \\
\hline Rio Pari & 63 & 73 & 96 & +10 & +23 & 80 & 73 & 68 & -7 & -4 \\
\hline Rio Santana & 420 & 379 & 406 & -41 & +27 & 17 & 38 & 32 & +21 & -6 \\
\hline BHPJ & 1578 & 1799 & 2012 & +221 & +213 & 61 & 52 & 50 & -9 & -2 \\
\hline
\end{tabular}

Tabela 05: Índice de Coesão de Mancha (COHESION) calculados por subbacia da Bacia Hidrográfica Paraguai/Jauquara - MT nos anos de 1997, 2007 e 2017.

\begin{tabular}{l|c|c|c|c|c}
\hline \multirow{2}{*}{ Subbacias } & \multicolumn{3}{c|}{ COHESION } & \multicolumn{2}{c}{ Redução e aumento } \\
\cline { 2 - 6 } & $\mathbf{1 9 9 7}$ & $\mathbf{2 0 0 7}$ & $\mathbf{2 0 1 7}$ & $\mathbf{1 9 9 7} \times \mathbf{2 0 0 7}$ & $\mathbf{2 0 0 7} \mathbf{~ 2 0 1 7}$ \\
\hline Córrego Cachoerinha & 99,98 & 99,95 & 99,96 & $-0,03$ & $+0,01$ \\
\hline Córrego Salobra & 99,97 & 99,94 & 99,95 & $-0,03$ & $+0,01$ \\
\hline Interbacia do Paraguai Médio & 99,94 & 99,94 & 99,95 & $+0,01$ & $+0,01$ \\
\hline Rio Branco & 99,94 & 99,93 & 99,86 & $-0,01$ & $-0,07$ \\
\hline Rio Diamantino & 99,96 & 99,95 & 99,95 & $-0,01$ & 0,00 \\
\hline Rio dos Bugres & 99,89 & 99,82 & 99,87 & $-0,07$ & $+0,05$ \\
\hline Rio Jauquara & 99,99 & 99,98 & 99,98 & $-0,01$ & 0,00 \\
\hline Rio Pari & 99,98 & 99,98 & 99,97 & $-0,01$ & 0,00 \\
\hline Rio Santana & 99,67 & 99,84 & 99,80 & $+0,17$ & $-0,04$ \\
\hline & $\mathbf{9 9 , 9 8}$ & $\mathbf{9 9 , 9 7}$ & $\mathbf{9 9 , 9 8}$ & $\mathbf{- 0 , 0 1}$ & $+\mathbf{0 , 0 1}$ \\
\hline
\end{tabular}

Neste sentido, os resultados apontam que as subbacias do Rio Santana e Interbacia do Paraguai Médio já eram as mais fragmentas no início do período de avaliação, em 1997 (Tabela 04). Contudo, a subbacia do Rio Santana foi a que mais recuperou seu estado de conservação em níveis de estrutura de paisagem (fragmentação e conectividade da área cobertura por vegetação nativa), entre 1997 a 2007, isso porque 
foi a que mais reduziu o NP e a que mais aumentou o LPI (Tabela 04) e o Índice de Coesão de Mancha (COHESION) (Tabela 05). Todavia, seu estado de conservação sofreu mudanças negativas, entre 2007 a 2017, pois com o aumento de 27 fragmentos pode ter influenciado na proporção do maior fragmento, pois o LPI e a COHESION reduziram consideravelmente ao longo do período.

Já as subbacias que mais reduziram o estado de conservação da área coberta por vegetação nativa foram: Rio Branco, Córrego Cachoerinha (embora tenha aumentado em $1 \%$ o LPI e 0,01 a COHESION), Rio Diamantino, Rio Jauquara e Rio Pari. Sendo que, a Rio Branco foi a subbacia mais suscetível em relação a redução do LPI e COHESION da classe vegetação natural ao longo das duas décadas.

Embora a Interbacia do Paraguai Médio tenha sido a subbacia da BHPJ que mais aumentou o NP no primeiro período de 1997 a 2007, não ocasionou reduções nos valores do LPI e COHESION (Tabela 4 e 5), pois pode ter apenas aumento no NP menores que já existiam no início do ano de 1997. Isso significa dizer que os fragmentos que aumentaram não foram originados do maior fragmento, o que consequentemente contribuem para que a cobertura vegetal tenha permanecido mais conectada/coesa, na subbacia, ao longo das últimas décadas.

Segundo Forman e Gordon (1986), a fragmentação da vegetação natural pode levar à criação de fragmentos isolados, que quando imersos em uma matriz antropizada são influenciados por ela, principalmente por meio do efeito de borda sobre o fragmento. Calegari et al. (2010) corroboram esse processo, explicando que esse tipo de efeito pode provocar alterações no microclima, perda e/ou alteração da biodiversidade da fauna e flora e em matas ciliares, pode ocasionar erosões e assoreamentos de canais fluviais.

O cálculo da métrica Distância Euclidiana do Vizinho Mais Próximo (ENN_MN) permitiu identificar que houve uma variação entre os períodos no grau de isolamento dos fragmentos pertencentes a paisagem da BHPJ, pois a métrica demonstrou que, do total de subbacias 6 (Rio Diamantino, Rio Pari, Interbacia do Paraguai Médio, Rio Santana, Córrego Salobra e Rio dos Bugres) diminuíram a distância entre os fragmentos. Isso indica que embora nessas subbacias tenha aumentado o NP houve algum tipo de restauração e/ou regeneração natural da área coberta dos fragmentos já existentes em 1997 e dos novos que surgiram até o ano de 2007 (Tabela 06).

Tabela 06: Redução e Aumento da Distância Euclidiana do Vizinho Mais Próximo (ENN_MN) por subbacia da Bacia Hidrográfica Paraguai/Jauquara - MT nos períodos de 1997 a 2007 e 2007 a 2017

\begin{tabular}{l|c|c|c|c|c|c|c|c}
\hline \multicolumn{7}{c}{ Redução e aumento da ENN_MN (km) } \\
\hline $\begin{array}{c}\text { Subabacias da } \\
\text { BHPJ }\end{array}$ & \multicolumn{9}{c|}{$\mathbf{1 9 9 7} \times \mathbf{2 0 0 7}$} & \multicolumn{4}{c}{$\mathbf{2 0 0 7} \mathbf{2 0 1 7}$} \\
\cline { 2 - 9 } & $\begin{array}{c}\text { Aumento } \\
(\mathbf{k m})\end{array}$ & $\begin{array}{c}\text { Aumento } \\
(\%)\end{array}$ & $\begin{array}{c}\text { Redução } \\
(\mathbf{k m})\end{array}$ & $\begin{array}{c}\text { Redução } \\
(\%)\end{array}$ & $\begin{array}{c}\text { Aumento } \\
(\mathbf{k m})\end{array}$ & $\begin{array}{c}\text { Aumento } \\
(\%)\end{array}$ & $\begin{array}{c}\text { Redução } \\
(\mathbf{k m})\end{array}$ & $\begin{array}{c}\text { Redução } \\
(\%)\end{array}$ \\
\hline Rio dos Bugres & & & 54,52 & 33,77 & 17,53 & 21,67 & & \\
\hline Rio Branco & 5,23 & 6,57 & & & 5,41 & 6,69 & & \\
\hline Córrego Salobra & & & 70,15 & 43,45 & 3,51 & 4,34 & & \\
\hline
\end{tabular}




\begin{tabular}{l|c|c|c|c|c|c|c|c}
\hline $\begin{array}{c}\text { Subabacias da } \\
\text { BHPJ }\end{array}$ & \multicolumn{4}{|c|}{1997 x 2007 } & \multicolumn{5}{c}{$\mathbf{2 0 0 7}$ x 2017 } \\
\hline & $\begin{array}{c}\text { Aumento } \\
(\mathbf{k m})\end{array}$ & $\begin{array}{c}\text { Aumento } \\
(\mathbf{\%})\end{array}$ & $\begin{array}{c}\text { Redução } \\
(\mathbf{k m})\end{array}$ & $\begin{array}{c}\text { Redução } \\
(\mathbf{\%})\end{array}$ & $\begin{array}{c}\text { Aumento } \\
(\mathbf{k m})\end{array}$ & $\begin{array}{c}\text { Aumento } \\
(\mathbf{\%})\end{array}$ & $\begin{array}{c}\text { Redução } \\
(\mathbf{k m})\end{array}$ & $\begin{array}{c}\text { Reduc̃ã } \\
(\mathbf{\%})\end{array}$ \\
\hline Rio Santana & & & 22,01 & 13,63 & 8,52 & 10,53 & & \\
\hline $\begin{array}{l}\text { Interbacia do } \\
\text { Paraguai Médio }\end{array}$ & 28,53 & 35,85 & & & & & 0,97 & 1,64 \\
\hline Rio Jauquara & 0,49 & 0,62 & & & 15,78 & 19,51 & & \\
\hline Rio Pari & & & 14,78 & 9,15 & 20,65 & 25,53 & & \\
\hline Rio Diamantino & 16,29 & 20,47 & & & & & 58,09 & 98,36 \\
\hline $\begin{array}{l}\text { Córrego } \\
\text { Cachoerinha }\end{array}$ & 29,05 & 36,50 & & & 9,48 & 11,72 & & \\
\hline \multicolumn{1}{c}{ Total } & $\mathbf{7 9 , 5 9}$ & $\mathbf{1 0 0}$ & $\mathbf{1 6 1 , 4 6}$ & $\mathbf{1 0 0}$ & $\mathbf{8 0 , 8 8}$ & $\mathbf{1 0 0}$ & $\mathbf{5 9 , 0 6}$ & $\mathbf{1 0 0 , 0 0}$ \\
\hline
\end{tabular}

Embora possa haver restauração e/ou regeneração natural dos fragmentos das subbacias, elas aumentaram o grau de isolamento dos fragmentos no segundo período de 2007 a 2017 (Tabela 06). Isso pode ter ocorrido devido ao aumento do NP e principalmente pela substituição dos remanescentes de vegetação por pastagem e agricultura durante o período (Figura 03 e Tabela 04).

Ao longo dos 20 anos as subbacias que só aumentaram o grau de isolamento dos fragmentos foram as bacias do Córrego Cachoerinha, em 48\%, Rio Jauquara, 20\%, e Rio Branco, em 13\% (Tabela 06). O isolamento dos fragmentos imersos em uma matriz altamente antropizada influencia os ciclos ecossistêmicos do habitat, o que, segundo Turner (1996), acarreta a persistência de muitas espécies em paisagens fragmentadas o que depende muito da qualidade da matriz, principalmente para o fluxo gênico e de recolonizarão de fragmentos isolados. Exemplo disso, são apresentados no estudo de Santos-Filho, da Silva e Sanaiotti (2008), que identificaram variações negativas na abundância e riqueza de pequenos mamíferos (roedores e marsupiais) e de artrópodes em fragmentos de Florestas Estacionais Semideciduais com formação Submontana no estado de Mato Grosso, imersos em uma matriz antropizada por pastagem.

As mudanças na composição ocorridas pela conversão da vegetação nativa em pastagem e agricultura contribuíram negativamente para o estado de conservação ambiental da BHPJ. Entre 1997 a 2007, há indícios de que em algumas das subbacias as alterações de configurações dos fragmentos foram melhores para a conservação do que no período seguinte, de 2007 a 2017. Isso significa que houve uma mudança na tendência de conservação da área, provavelmente por influência da regulamentação da Lei Federal 12.651 de 08 de janeiro de 2012.

Essa nova regulamentação legal para a proteção da vegetação nativa brasileira prevê alterações nos critérios técnicos de delimitação de alguns tipos de Áreas de Preservação Permanente (APP), que resultam em reduções de áreas protegidas na forma de nascentes e topos de morro. Além disso, em imóveis rurais também se prevê o uso consolidado com redução na faixa de recomposição de floresta variável com o módulo fiscal e pela adequação de Reservas Legais (RL) (Brasil, 2012). Apesar desses potenciais efeitos de redução na proteção de florestas, no período entre 2007 a 2017, há indícios de 
que grande parte dos remanescentes de vegetação é composto por APPs em áreas onde o relevo é suavemente ondulado a escarpado, o que potencialmente inviabiliza o uso da terra para atividades agrícolas.

\section{Conclusões}

Verificou-se que os remanescentes de vegetação foram convertidos ao longo dos 20 anos analisados para Agricultura e principalmente para Pastagem e entre os anos de 1997 e 2007. A substituição ocorrida facilitou os processos de fragmentação e isolamento da vegetação em algumas subbacias da BHPJ dentre elas, Rio Branco, Córrego Cachoerinha, Rio Diamantino, Rio Jauquara, Rio Pari e Interbacia do Paraguai Médio. Essa situação é preocupante, pois as áreas convertidas deixaram de exercer funções essenciais para a manutenção da qualidade ambiental dos recursos naturais da BHPJ e ainda podem influenciar na alteração do pulso de inundação do Pantanal matogrossense.

Sugere-se realizar estudos complementares que busquem avaliar a qualidade ambiental da paisagem visando a interpretação das interações das unidades antropizadas com os ambientes naturais formadoras de mosaicos heterogêneos que compõem a paisagem da BHPJ. Os resultados deste estudo podem auxiliar nas tomadas de decisão quanto à gestão adequada do uso e cobertura da terra e recursos hídricos, visando a manutenção dos ecossistemas naturais.

\section{Referências Bibliográficas}

AMORIM, R. R.; OLIVEIRA, R. C. As unidades de paisagem como uma categoria de análise geográfica: o exemplo do município de são Vicente-SP. Revista Sociedade \& Natureza, v. 2, n. 20, p. 177-198, 2008.

BRASIL. Agência Nacional de Águas, 2018. Superintendência de Gestão da Rede Hidrometeorológica. Nome do documento, 2018. Disponível em:

$<$ http://www.snirh.gov.br/hidroweb/publico/baixar_documento.jsf > . Acesso em 27 jul. 2018.

Brasil. Decreto n 87222 de 31 de maio de 1982. Cria as Estações Ecológicas do Seridó, Serra das Araras, Guaraqueçaba, Caracaraí e dá outras providências. Diário Oficial da União, Brasília, DF, 31 mai. 1996. Disponível em:

$<$ http://www.planalto.gov.br/ccivil_03/decreto/1980-1989/D87222.htm>. Acesso em 06 jan. 2019.

Brasil. Lei Federal 12.651 de 25 de maio de 2012. Proteção de vegetação nativa. Diário Oficial da União, Brasília, DF, 25 mai. 2012. Disponível em:

$<$ http://www.planalto.gov.br/ccivil_03/_ato2011-2014/2012/lei/112651.htm>. Acesso em 23 out. 2018.

BRASIL. Ministério do Meio Ambiente e Instituto Brasileiro de Geografia. Mapa de Biomas do Brasil. Rio de Janeiro: IBGE, 2004. Escala 1: 500.0000. 
CALEGARI, L.; MARTINS, S. V.; GLERIANI, J. M.; SILVA, E.; BUSATO, L. C. Análise da Dinâmica de Fragmentos Florestais no Município de Carandaí, MG, para Fins de Restauração Florestal. Revista Árvore, v. 34, n. 5, p. 871-880, 2010.

CÂMARA, G.; SOUZA, R.C.M.; FREITAS U. M.; GARRIDO, J. C. P. Spring: Integrating Remote Sensing and GIS with Object-Oriented Data Modelling. Computers and Graphics, v. 20, n. 3, p. 395-403, 1996.

CUNHA, J. M. P. Dinâmica migratória e o processo de ocupação do Centro-Oeste brasileiro: o caso de Mato Grosso. Revista brasileira de estudo de população, v. 23, n.1, p. 87-107, 2006.

ESRI. ArcGIS Desktop: release 10.3. Redlands, CA: Environmental Systems, 2007.

FENNER, W.; MOREIRA, P. S. P.; FERREIRA, F. S.; DALLACORT, R.; QUEIROZ, T. M.; BENTO, T. S. Análise do balanço hídrico mensal para regiões de transição de Cerrado-Floresta e Pantanal, Estado de Mato Grosso. Revista Acta, v. 3, n.1, p. 72-85, 2014.

Ferreira, J. C. V. Mato Grosso de seus Municípios. Cuiaba: Editora Burit. 2001. 660 p.

FORMAN, R. T. T.; GODROM, M. Landscape ecology. New York: John Willey. 1986. $619 \mathrm{p}$.

HARDT, E.; SANTOS, R. F.; PEREIRA-SILVA, E. F. L. P. Evaluating the ecological effects of the social agent scenarios for a housing development in the Atlantic Forest. Ecological Indicators, v. 36, n. 36, p. 120-130, 2014.

IBGE. Instituto Brasileiro de Geografia e Estatística. Manual técnico da vegetação brasileira. 3 ed. Rio de Janeiro: IBGE, 2012. p. 45-168.

INMET. Instituto Nacional de Meteorologia. BDMEP - Banco de Dados Meteorológicos para Ensino e Pesquisa, 2020. Disponível em: <

http://www.inmet.gov.br/portal/index.php?r=bdmep/bdmep>. Acesso em 25 mar de 2020.

KRUSCHE, A. V.; BALLESTER, M. V. R.; VICTORIA, R. L.; BERNARDES, M. C.; LEITE, N. K.; HANADA, L.; VICTORIA, D. C.; TOLEDO, A. M.; OMETTO, J. P.; MOREIRA, M. Z.; GOMES, B. M.; BOLSON, M. A.; NETO, S. G.; BONELLI, N.; DEEGAN, L.; NEILL, C.; THOMAS, S.; AUFDENKAMPE, A. K.; RICHEY, J. E. Efeitos das mudanças do uso da terra na biogeoquímica dos corpos d'água da bacia do Rio Ji-Paraná, Rondônia. Revista Acta Amazônica, v. 35, n. 2, p. 197-205, 2005.

MCGARIGAL, K.; MARKS, B. J. FRAGSTATS: spatial pattern analysis program for quantifying landscape structure. Gen. Tech. Report PNW-GTR-351, USDA Forest Service, Pacific Northwest Research Station, Portland, OR, 1995. 122 p.

METZGER, J. P. O que é ecologia da paisagem? Biota Neotropica, v. 1, n.1, 2001, p. 19. 
MORAIS, R. P.; CARVALHO, T. M. Cobertura da terra e parâmetros da paisagem no município de Caracaraí-Roraima. Revista Geografia Acadêmica, v. 7, n. 1, p. 46-59, 2013.

NEVES, L. F. S.; NEVES, S. M. A. S.; NEVES, R. J. Geotecnologias e métricas aplicadas na análise da paisagem da bacia do rio Aguapeí/MT, Brasil. Revista Geo UERJ, v. 2, n. 25, p. 397-418, 2014.

OLIVEIRA FILHO, P. C.; DUTRA, A. M.; CERUTI, F. C. Qualidade das Águas Superficiais e o Uso da Terra: Estudo de Caso Pontual em Bacia Hidrográfica do Oeste do Paraná. Revista Floresta e Ambiente, v. 19, n. 1, p. 32-43, 2012.

OLIVEIRA, P. P. A.; CORSI, M. Recuperação de pastagens degradadas para sistemas intensivos de produção de bovinos. Circular técnica 38. São Carlos, SP, 2005.

Disponível em:

$<$ https://ainfo.cnptia.embrapa.br/digital/bitstream/CPPSE/15659/1/Circular38.pdf> Acesso em: 04 de janeiro de 2019.

PEREIRA, J. L. G.; BATISTA, G. T.; THALÊS, M. C.; ROBERTS, D.; VENTURIERI, A. Métricas da Paisagem na caracterização da evolução da ocupação da Amazônia. Revista Geografia, v. 26, n. 1, p. 59-90, 2001.

PESSOA, S. P. M.; GALVANIN, E. A. S.; KREITLOW, J. P.; NEVES, M. A. S.; NUNES, J. R. S.; ZAGO, B. W. Análise espaço-temporal da cobertura vegetal e uso da terra na Interbacia do Rio Paraguai Médio-MT, Brasil. Revista Árvore, v. 37, n.1, p. 119$128,2013$.

PINTO, L. V. A.; FERREIRA, E.; BOTELHO, S. A.; DAVIDE, A. C. Caracterização física da bacia hidrográfica do Ribeirão Santa Cruz, Lavras, MG e uso conflitante da terra em suas áreas de preservação permanente. Revista Cerne, v. 11, n. 1, p. 46-61, 2005.

PIVELLO, V. R.; METZGER J. P. Diagnóstico da pesquisa em ecologia de paisagens no Brasil (2000-2005). Revista Biota Neotropica, n. 3, v. 7, p. 21-29, 2007.

QGIS Development Team. QGIS 2.14.0 Essien. Geographic Information System. Open Source Geospatial Foundation Project, 2016.

RIBEIRO, H. V.; GALVANIN, E. A. S.; PAIVA, M. M. Análise das pressões antrópicas na bacia Paraguai/Jauquara-Mato Grosso. Revista Ciência e Natura, v. 39, n. 2, p. 378389, 2017.

RIVERO, S.; ALMEIDA, O.; ÁVILA, S.; OLIVEIRA W.; Pecuária e desmatamento: uma análise das principais causas diretas do desmatamento na Amazônia. Revista Nova Economia, n. 19, v. 1, p. 41-66, 2009.

ROMERO, A. C.; ISSII, T. M.; PEREIRA-SILVA, E. F. L.; HARDT, E. Effects of urban sprawl on forest conservation in a metropolitan water source área. Revista Árvore. v. 42, n. 1, p. 1-11, 2018. 
ROSOLEN, V.; RESENDE, T. M.; BORGES, E. N.; FRARE, C. T.; MACHADO, H. A. Impactos da substituição da vegetação original do Cerrado brasileiro em sistemas agrícolas: alteração do carbono orgânico do solo e $\delta^{13} \mathrm{C}$. Boletín del Instituto de Geografia, v. 1, n. 79, p. 39-47, 2012.

SANTOS-FILHO, M.; DA SILVA, D. J.; SANAIOTTI, T. M. Edge effects and andscape matrix use by a small mammal community in fragments of semideciduous submontane forest in Mato Grosso, Brazil. Brazilian Journal of Biology, v. 68, n. 4, p. 703-710.

TUCCI, C. E. M. Hidrologia: Ciência e Aplicação. 2. ed. Porto Alegre: Universidade Federal do Rio Grande do Sul, 2001. 943 p.

TURNER, I. M. Species loss in fragments of tropical rain forest: a review o the evidence. Journal of Applied Ecology, v. 33, n. 2, 1996, p. 200-209.

WIENS, J. A. Is landscape sustainability a useful concept in a changing world? Revista Landscape Ecology, v. 1, n. 28, p. 1047-1052, 2012.

Angélica Aparecida Dourado da Costa

Mestra em Ambiente e Sistema de Produção Agrícola, pela Universidade do Estado de Mato Grosso - UNEMAT, graduada em Ciências Biológicas pelo Instituto Federal do Mato Grosso - IFMT.

Endereço: Campus Universitário Professor Eugênio Carlos Stieler de Tangará da Serra Rodovia MT - 358 (Avenida Inácio Bittencourt Cardoso), Km 07 (s/n) Jardim Aeroporto, Tangará da Serra - MT, CEP: 78300-000 Caixa Postal 287

ORCID: https://orcid.org/0000-0002- 9104-9429

Email: angelica.dourado.jna@gmail.com

\section{Edinéia Aparecida dos Santos Galvanin}

Pós-doutora em Estatística Espacial pela Universidade do Minho (UMinho Portugal) e em Geografia pela Universidade Federal do Rio de Janeiro (UFRJ), doutora e mestra em Ciências Cartográficas pela Universidade Estadual Paulista (UNESP), graduada em Matemática também pela UNESP. Atualmente é professora Assistente Doutora da UNESP (Campus de Ourinhos) e docente permanente do programa de pós-graduação stricto sensu em Geografia (Mestrado Profissional) da UNESP e docente permanente do programa de pós-graduação stricto sensu em Ambiente e Sistemas de Produção Agrícola da Universidade do Estado de Mato Grosso.

Endereço: Unesp - Campus de Ourinhos, Av. Renato da Costa Lima, 451 - Ville de France, Ourinhos - SP, CEP: 19903-302.

ORCID: https://orcid.org/0000-0002-6678-9599

Email: edineia.galvanin@unesp.br 


\section{Elisa Hardt Alves Vieira}

Doutora em Engenharia Civil - área de Recursos Hídricos, Energéticos e Ambientais pela Universidade Estadual de Campinas - UNICAMP, com título de Doutora pela Universidad Complutense de Madrid, Mestre em Recursos Florestais pela Escola Superior de Agricultura Luiz de Queiroz da ESALQ - USP e graduada em Ciências Biológicas pela Universidade Federal de São Carlos - UFSCar. Atualmente é professora na Universidade Federal de São Paulo - UNIFESP - Campus Diadema e pesquisadora colaboradora no Departamento de Ecologia da UCM.

Endereço: Universidade Federal de São Paulo, Campus Diadema, Departamento de Ciências Ambientais. Laboratório de Ecologia Aplicada e Conservação - LECON Grupo de Ecologia de Paisagem e Planejamento da Conservação - Rua Professor Arthur Riedel, 275 Eldorado, Diadema - SP, CEP: 09972270.

ORCID: http://orcid.org/0000-0002-1654-0218

Email: elisa.hardt@unifesp.br

Recebido para publicação em março de 2019 Aprovado para publicação em janeiro de 2020 